\title{
Perceiving That We See and Hear in Aristotle's De Anima III 2
}

\author{
Roberto Grasso ${ }^{1}$
}

This article tackles Aristotle's discussion of the activity of 'perceiving that we are seeing and hearing' in De Anima III 2 425b12-25. Its central claim is that the passage postulates a particular type of perception, where a certain content $F$ is perceived in the absence of causal interactions between sense organs and actually perceptible $F$-objects. In Aristotle's view, the 'underlying' colors being seen must be included in the perception of one's own seeing, but such colors are merely phenomenal and thus deprived of the causal powers by which perceptible objects physically interact with sense organs. The paper also contends that it makes no difference to the aim of the passage whether $\alpha$ li $\sigma \theta \eta \sigma r \zeta$ and ö $\psi 1 \varsigma$ describe perceptual activities or capacities, and that Aristotle's much-discussed 'regress argument' can be explained without taking the expression 'perceiving that we see (or hear, etc.)' as an awkward description of the intrinsic 'phenomenal awareness' belonging to first-order perceiving.

\section{Introduction}

Aristotle's treatment of the activity of 'perceiving that we see and hear' in $D A$ III 2 (425b12-25) has sparked a complex debate among his commentators. The arguments he expounds are difficult to follow and even the type of 'perceiving' that constitutes the main topic of the passage has been interpreted in radically different ways. In addition, the ambiguity of some of the key terms Aristotle uses in the passage makes it difficult to understand whether the investigation is about the capacity or the activity responsible for one's perception that one

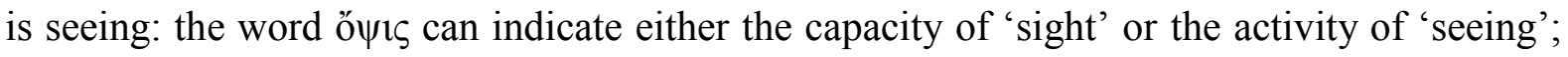

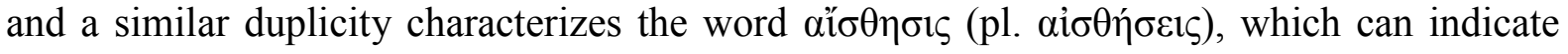
either 'senses' or 'sensations'.

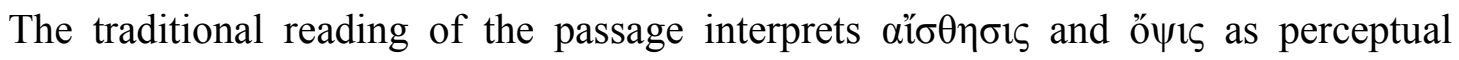
capacities. Under this premise, Aristotle is thought to offer two arguments against the hypothesis that the sense responsible for one's perception of one's own seeing is different from sight. The first argument (425b12-15) would be based on the idea that the 'underlying' color

\footnotetext{
${ }^{1}$ The present work was carried out with the support of FAPESP, São Paulo Research Foundation (Process no.2016/02485-0).
} 
being seen (or the sound being heard, etc.) must be included in one's perception of one's seeing (or hearing, etc.). In the traditional reading, the necessary inclusion of the 'underlying' color entails that two senses (sight and the putative 'different sense') are about the same object (about colors, or sounds, etc.), which is supposed to be at odds with the claim that colors are exclusive to sight (and sounds to hearing, etc.) — the so-called doctrine of 'proprietary objects' expressed in DA II 6 (418a7-16). Continuing along the same lines, in 425b15-17 Aristotle would then add a 'regress argument' to corroborate the point: if we insist on the 'different sense hypothesis', we should then face the necessity of postulating a further sense responsible for "perceiving that we perceive that we see' and so on, ad infinitum; to avoid the regress, we should assume that sight is capable of perceiving itself. Aristotle would finally (b17-20) consider a possible objection about the coloration of 'that which sees' ( $\tau$ ò ó $\rho \tilde{\omega} v$ ), solving it by admitting that 'perceiving by sight' is not limited to 'seeing' (b20-23); and that 'that which sees' is somewhat colored (b23-25). ${ }^{2}$

Several aspects of the traditional interpretation sketched above have been criticized by commentators. A classic study in this sense is Kosman (1975), who argued that the traditional reading attributes to Aristotle two badly conceived arguments for a conclusion that apparently contradicts what he says in another work (in Somn. 2 455a17-20, Aristotle denies that that "we see that we see' by sight). ${ }^{3}$ As we shall see, the disagreement among scholars has increased considerably since that study. Due to the number of contradictory critical remarks one finds in the literature, it is fair to say that readers are requested to make difficult decisions at each turn of this puzzling section of $D A$ III 2 .

In this paper, I shall firstly survey the basic points on which scholars disagree, organizing them around three research questions. I shall then try to offer a plausible reply to those questions by initially skipping the difficult first section (425b12-17): in an attempt to 'reverse-engineer' Aristotle's reasoning, I shall begin by focusing on the puzzle of the coloration of 'that which sees' and the related remarks that conclude the overall argument about

\footnotetext{
${ }^{2}$ Cf. Hicks, R. D. (1907), Aristotle, De Anima. Cambridge University Press, 433-434; Ross, W.D. (1961). Aristotle, De Anima. Edited, with introduction and commentary. Clarendon Press, 274-5; Polansky, R.M. (2007). Aristotle's De Anima. Cambridge University Press, 381-383.

${ }^{3}$ Cf. Kosman, L. A. (1975). Perceiving that We Perceive: On the Soul III, 2. The Philosophical Review, 84(4), 499-505. At that time, doubts about the inclusion of the underlying color, which supposedly works as a premise of the first argument, had been already formulated by Hicks (1907: 435), and Hamlyn, D.W. (1968, 1993), Aristotle De Anima, Oxford University Press, 121-122. The latter also lamented that it is impossible to make sense of the idea that 'perceiving that we see' entails that we perceive 'that which sees' (ibid., 123).
} 
perceiving that we see and hear (425b17-25). By doing so, I shall show that even if we maintain a neutral stance with regard to the controversy between the activity and capacity reading of

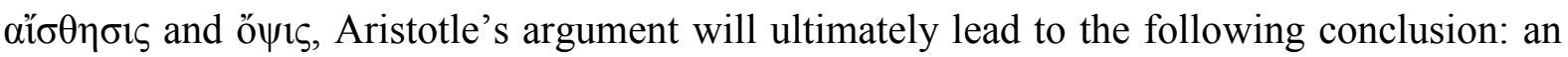
activity different from seeing (or hearing, etc.), and thence a power different from the ability to see (or to hear, etc.), is required to account for the operation of 'perceiving one's own seeing (or hearing, etc.)' ${ }^{4}$ The conclusion is reached under the premise that seeing (or hearing, etc.) means perceiving a visible (or hearable, etc.) object 'per se', i.e., perceiving what is visible (or hearable, etc.) in actuality in virtue of the stimulation the latter object causes on the eye (or the ear, etc.). As I shall argue, Aristotle maintains that the operation of 'perceiving that we see and hear' postulates a peculiar type of 'accidental' perception, in which some content $F$ is perceived in the absence of a genuinely physical causal interaction with an $F$-object: in perceiving our own seeing (or hearing), we perceive the abstract content of those mental states, which are just characterized by causally powerless phenomenal properties.

Since this type of perception does not work according to the type of causal mechanism at play in 'per se' instances of perceiving — such as seeing or hearing — we should be wary of describing Aristotle's 'perception that we see' as a higher-order theory of perceptual awareness. On the other hand, I shall also reject the idea, supported by some commentators, that 'perceiving that we see and hear' refers to the intrinsic phenomenal awareness that belongs to seeing and hearing - a necessary aspect of first-order perception rather than a second-order perception directed at it. As I shall clarify, Aristotle's reasoning - including the controversial regress argument of 425b15-17 — works without assuming that some notion of 'intrinsic phenomenal awareness' is at stake.

What Aristotle has in mind might in fact be the 'awareness' distinguishing attended from unattended perceptual experience. The notion can be illustrated by the typical contrast between the perceptual experience of an absent-minded driver and the perceptual experience of a driver deliberately attending to her own perception. As contemporary philosophers have recently begun to realize, the mechanism behind such awareness is different from the one responsible for (first or higher-order) perceptual representations. This difference displays

\footnotetext{
${ }^{4}$ In what follows, I shall assume that by 'we perceive that we see and hear' Aristotle means 'as we see, we perceive that we see; as we hear, we perceive that we hear' (cf. Ross 1961: 274-5), rather than 'as we are seeing and hearing, we perceive that we are both hearing and seeing together' (cf. Polanksy, 2007: 381). If he were asking the latter question, it would seem obvious that no individual sense can detect its own and another sense's operation by itself - cf. Gregoric, P. (2007). Aristotle on the Common Sense. Oxford University Press, 175.
} 
striking similarities with the difference between types of perception introduced by $D A$ III 2's reflection on how we perceive that we see and hear.

\section{The Questions}

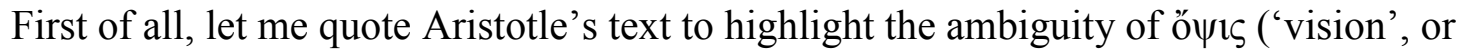

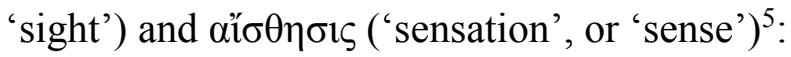

$\{1\}$ Since we perceive that we are seeing and hearing, $\{2\}$ it is necessary that one perceives that one

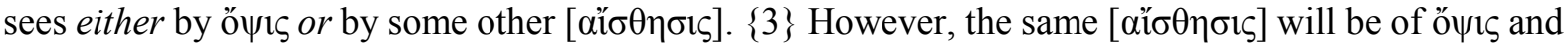

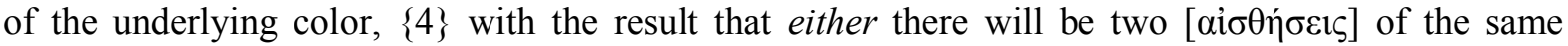

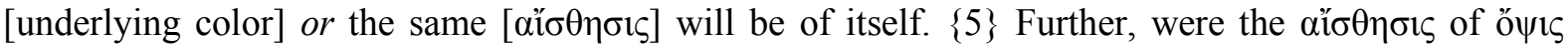

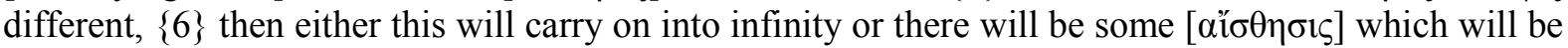

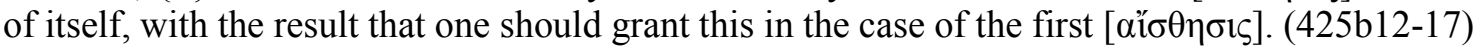

In $\{1\}$, Aristotle appears to simply assume that 'we perceive that we see (and hear)' no hypothesis about accessing that information by means of non-perceptual types of cognition is considered at any stage of the argument. We can cautiously take this to indicate that the focus of the discussion is the perceptual way of knowing that we are seeing and hearing - the possibility that one can think (or imagine or desire) that one sees (and hears) is not precluded, but it is not the object of the discussion. ${ }^{6}$

We might organize the problems raised by commentators with regard to Aristotle's reasoning in $\{2\}-\{6\}$ around three research questions:

- Q1: Is Aristotle arguing in favor of one of the options presented in $\{2\}$ and $\{4\}$ ? If not, what is the function of the 'object inclusion' remark he makes in $\{3\}$ ?

- Q2: What is the rationale behind the regress in $\{5\}-\{6\}$ ?

- Q3: More generally, is Aristotle's argument about senses (perceptual capacities), as assumed by the traditional interpretation, or about sensations (perceptual activities)?

\footnotetext{
${ }^{5}$ The translation is based on Shields (2016), Aristotle De Anima. Oxford University Press, with several modifications (as is common practice among translators, Shields renders dï $\sigma \theta \eta \sigma ı \varsigma$ as 'sense' and ö $\psi 1 \varsigma$ as 'sight').

${ }^{6} \mathrm{Cf}$. Gregoric (2007: 175-176), who thinks that Aristotle is reasoning under the premise that there are only individual senses. While this seems to be the case at the beginning of the argument, I'm not convinced by Gregoric's idea that Aristotle is excluding any reference to his notion of the common sense because he wants to reason about the challenge posed by the Charmides in a way that is fair to Plato. For reasons that I am going to clarify, I believe that Aristotle is in fact arguing that a special ability, different from the one involved in the perception of 'proprietary' objects, should be postulated in order to explain how we perceive that we see (and hear, etc.).
} 
With regard to the first question, there seems to be a certain consensus around the idea that, at least until the regress argument in $\{6\}$, Aristotle is not trying to favor one of the options introduced in $\{2\}$ and re-proposed in $\{4\}$, since both are problematic. ${ }^{7}$ The consensus in not unanimous, though. In fact, it might be argued that the development of Aristotle's reasoning does not raise any real issue for either of the options being enumerated. In particular, the efficacy of invoking the doctrine of proprietary objects is questionable: Aristotle does claim that each of the five senses has the proprietary power of per se perceiving a certain class of objects (DA II 6 418a7-16); however, this does not rule out the possibility of accessing, by accidental perception, the proprietary objects of a certain sense by some other sense. Thus, flavors, proprietary objects of taste, can be 'accidentally' perceived by sight, as Aristotle has explicitly argued some lines ago (DA III 1 425a30-b4). ${ }^{8}$ Furthermore, there is an additional way to avoid the traditional accusation of violating the doctrine of proprietary objects: one might suppose that the 'other $\alpha$ i $\sigma \theta \eta \sigma ı$ ' is a second, higher-order sense of sight, which would thus be as capable of perceiving the underlying color as the first, lower-order sight. ${ }^{9}$ As a consequence, it would seem that Aristotle is not yet entitled to discard any of the hypothesis posed in $\{4\}$, in spite of the 'object inclusion' remark made in $\{3\}$, because none of them is

\footnotetext{
${ }^{7}$ In this regard, cf. Johansen, T.K. (2005). In Defense of Inner Sense: Aristotle on Perceiving That One Sees. Proceedings of the Boston Area Colloquium in Ancient Philosophy, 21, 243-244. Johansen argues that the 'different sense' hypothesis is afflicted by the tension it generates with the doctrine of proprietary objects, and the 'same sense' hypothesis by the fact that Aristotle claims in II 5 that, despite containing fire and the other elements, sense organs do not perceive themselves (he further mentions the 'worry aired in Plato's Charmides $165 \mathrm{C}$ ff., namely, that if knowledge is of something, it ought to be of something other than itself'). A more radical view is proposed by Osborne, C. (1983). Aristotle, De anima 3.2, How do We Perceive that We See and Hear? Classical Quarterly, 33, 401-2, 406-7. Osborne argued that the first part of III 2 as a whole is just exploring three options - i.e., that we perceive that we see (a) by a sense other than sight; (b) by sight but not in virtue of seeing; (c) by sight, in virtue of seeing - and that only considering the chapter as a whole can one finally exclude that we perceive that we see by sight (in agreement with Somn.2). A similar skepticism with regard to the outcome of the section of III 2 on perceiving that we see and hear is expressed by Gregoric (2007: 175181 , cf. note 6 above).

${ }^{8}$ Osborne (1983: 402) casts doubt on the interpretation by noting that "nothing is said about "proper" objects, and in the previous chapter we had just been considering objects perceived by more than one sense'.
}

${ }^{9}$ Cf. Caston (2002: 765-6). 
actually problematic. ${ }^{10}$ This reading, however, raises the question of the function we should assign to $\{3\}$ in the reconstruction of Aristotle's argument. ${ }^{11}$

The relevance of the second question has been highlighted by Kosman (1975), who proposed for the first time that the regress argument requires a change of perspective with regard to what 'perceiving that we see' means. If Aristotle's 'perception that we see and hear' were second-order reflective consciousness, there would be no clear reason to postulate anything more than a first, higher-order act of perception directed at the lower-order act of perceiving that is being detected (our seeing, or hearing, etc.). What we would be looking for would be, through the traditional interpretation, the perception of the first-order act of vision; thus, we could be satisfied by postulating just one higher-order act of perceiving, without any need to demand the automatic re-iteration of the initial request at each level (the capacity to 'perceive the perception of the first-order act of vision'; and then the capacity to perceive the latter, and so on). ${ }^{12}$ To avoid the problem, Kosman argued that by 'perceiving that we see' Aristotle does not indicate the self-consciousness or reflective awareness of our own seeing or hearing obtained by a separate perceptual operation, but, rather, the 'non-reflective consciousness' implicitly characterizing seeing (and any other perceiving) qua mental. ${ }^{13}$

By working on both the second and third questions, Caston (2002) proposed a more radical revision of the passage, arguing that Kosman's proposal about the regress argument

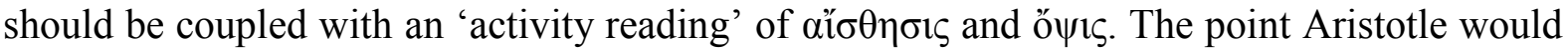
be making here, for Caston, is that the 'intrinsic consciousness' of seeing (and hearing, etc.) is

${ }^{10}$ For Gregoric (2007: 178-9), the reference to the doctrine of proprietary objects is effective against the hypothesis of two senses of the same object, but only because Aristotle dialectically reasons under the premises of Plato's Charmides - i.e., excluding the common sense. I take the passage the other way round: I believe that Aristotle does not think that the hypothesis of two senses of the same object is problematic because, in virtue of his own views about the unity of the perceptual apparatus, one sense can accidentally perceive another sense's object.

${ }^{11}$ Caston (2002: 771) has observed, in this regard, that the 'object inclusion' remark is 'gratuitous', unless taken as indication of the fact that the 'perceiving that we see' Aristotle has in mind is the intrinsic phenomenal awareness of any first-order perceptual activity (2002: 755-759, 769, 773-775).

${ }^{12}$ Kosman (1975: 501-502; 2005: 280-281).

${ }^{13}$ Scholars proposing the 'intrinsic perceptual consciousness' interpretation claim that the latter aspect is theorized by Aristotle to demarcate perception from the mere being physically affected by perceptible objects, and thence solve a problem mentioned at the end of DA II 12 Cf. Kosman, 1975: 507-511; Caston, 2002: 755-757; Corkum, P. (2010). Attention, Perception, and Thought in Aristotle. Dialogue, 49(2), 204-205. The connection with DA II 12 is rejected by Johansen (2005: 256-257). Note that supporters of this interpretive approach tend to assume that for Aristotle physical processes of the same type (a 'transduction', or a literal assimilation) take place both in the sense-organs and in the inanimate media of perception. 
achieved by means of a higher-order type intentional act that has a different content in comparison to the first-order type act, but does not count as a separate second token (Caston 2002: 768-773). In this regard, Caston argued that the idea that the sense of sight is 'about itself' - the result Aristotle would obtain at the end of the section according to the traditional

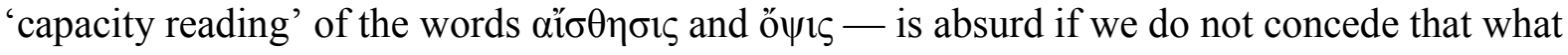
the perceptual capacity is about is, in fact, its own activity. ${ }^{14}$

The important drawback of the 'intrinsic consciousness' interpretation, advanced in different fashions by Caston and Kosman, is that it requires an unconvincing reading of the expression 'perceiving that we see', which does not naturally suggest the awareness 'intrinsically belonging to' seeing (and thence, in this sense, 'of' seeing), but, rather, the second-order perception by which we are aware that seeing is taking place. ${ }^{15}$ In this regard, a justification for Aristotle's expression might be supplied by arguing that he is trying to 'cut down the middle' of the dichotomy generated by the current debate 'between those who take consciousness to be an intrinsic feature of mental states and those who think it consists in a higher-order thought or perception' (Caston, 2002: 752). The awkwardness of the expression remains, however: Aristotle's starting point might at best be read as 'we are (perceptually) aware that we see and hear', but maintaining that this phrase is equivalent to 'our seeing is (perceptually) aware' still requires too much of a stretch.

One should proceed with similar caution in relation to the debate surrounding the

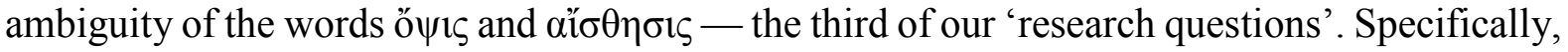
it seems that the 'old' capacity reading of alo $\theta \eta \sigma r \varsigma$ is no less — and, in fact, more — plausible than the 'new' activity reading. In $D A$ III 1-2, Aristotle is generally interested in perceptual

\footnotetext{
${ }^{14}$ More precisely, Caston (2002: 765-768) emphasizes that it would be absurd to claim that what is being perceived is the capacity of seeing itself (what he calls 'extreme capacity reading'). As he himself recognizes (ibid.), though, the defender of the capacity reading need not accept that perceiving the capacity amounts to perceiving that a certain subject is able to perceive - one can argue that the capacity perceives that the subject is seeing (what Caston labels the 'moderate capacity view'). The latter, however, requires a shift in the referent of the expression 'the same ( $\alpha$ it $\sigma \theta \eta \sigma ı)$ ) is of the same

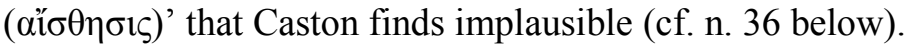

${ }^{15}$ As Osborne (1983: 405) rightly remarks. Kosman (1975: 514-517) had tried to justify the equivalence by invoking the thesis that 'to perceive is just to be aware of being affected' (a point related to his reading of the finale of $D A$ II 12 ibid. 509-511, 518); and that such awareness cannot be separated by an awareness of the object being perceived (since it is intrinsically intentional as well as 'transparent' to itself). Regarding the latter point, Kosman (ibid.: 513-514) refers to the claim that the act of the sensible being perceived and the act of the sense perceiving it are identical (DA III 2 425b26-426a26), which in his view seems to entail that 'perceiving red' is equal to both 'perceiving red's actuality as it affects sight' and 'perceiving sight's seeing red'. Kosman's arguments are rejected by Caston (2002: 782-785) and Johansen (2005: 256-257).
} 
capacities, aiming to show that the model of five jointly working senses is capable of explaining the complex perceptual activities we are able to perform - and in fact is postulated by them. This suggests that in the first part of III 2 , he considers the phenomenon of "perceiving that we see' from the same 'capacity' standpoint. ${ }^{16}$ Furthermore, it is possible to note that none of the occurrences of ow $\psi 1 \varsigma$ that refer to the activity of 'seeing' in Aristotle's works are from the De Anima, and that in several passages in this work Aristotle contrasts the act of seeing and the

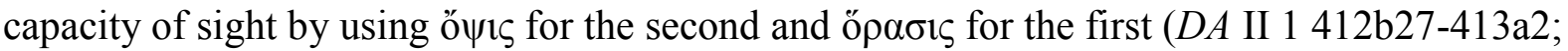
III 2 426a12-15; 3 428a6-7). ${ }^{17}$

In the rest of the paper, I shall argue that, with regard to the logic of Aristotle's argument about perceiving that we see and hear, we can suspend judgment with regard to the third

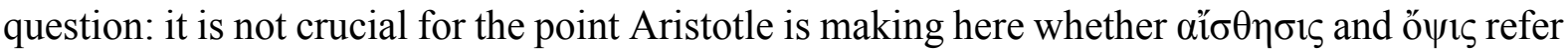
to perceptual activities or capacities, and his argument works in both cases. Concerning the first question, I shall agree with most commentators that Aristotle does not favor any of the options presented in $\{2\}$ and $\{4\}$, but I will provide an explanation of the object inclusion remark made in $\{3\}$ that does not involve the doctrine of 'proprietary objects'. Finally, I shall show that the regress argument in $\{6\}$ can be effectively explained, without accepting that Aristotle's expression 'perceiving that we see' is a clumsy description of the 'intrinsic perceptual awareness that belongs to seeing'. ${ }^{18}$

\section{The Puzzle About the Coloration of 'That Which Sees'}

In an attempt to 'reverse-engineer' the argument Aristotle proposes in $\{1\}-\{6\}$, I shall begin from the end and look at the final section of our passage, which follows the controversial

\footnotetext{
${ }^{16} \mathrm{Cf}$. the reconstruction of the context offered by Johansen (2005: 235-238). Caston (2002: 763) himself admits that the context in which the section occurs mainly deals with capacities.

${ }^{17}$ Cf. Johansen (2005: 240-241).

18 Johansen (2005: 244-5) has tried to solve Kosman's problem without abandoning the traditional reading of the regress argument, but his proposal only works if the argument is taken as a potential explanatory regress about faculties, rather than as a regress unavoidably triggered by the actual recursive necessity that each newly introduced act of perceiving must be perceived (cf. note 37 below). Gregoric (2007: 178-9) argues that Aristotle's regress is based on the assumption that 'the activity of every sense is perceived', which works under the premise that only individual senses exist but would not hold for the common sense. What is not clear, however, is why the assumption should hold for the individual senses in the first place.
} 
regress argument. Aristotle begins this section by raising a 'puzzle' ( $\dot{\alpha} \pi$ opí $\alpha$ ) about the coloration of 'that which sees' ( $\tau$ ò ó $\rho \tilde{\omega} v) .{ }^{19}$

$\{7\}$ There is a puzzle, however: if perceiving by ö $\psi 1 \varsigma$ is seeing and what is seen is either color or what possesses color, if one is to see that which sees, then that which sees will have color in a primary way. $\{8\}$ Now, it is evident that perceiving by ö $\psi 1 \varsigma$ is not one thing; for even when we are not seeing, we still discriminate darkness from light by ö $\psi 15$, though not in the same way. $\{9\}$ And, moreover, that which is seeing is in a sense colored. For the sensory organ is receptive, in each case, of the perceptible without the matter. (425b17-24, Shields' translation, modified)

Aristotle avoids the puzzle by leaving open the possibility that we perceive that we see by sight while denying that we see that we see. In $\{8\}$, he stresses that even when we are not seeing it is still by sight that we discriminate darkness from light, 'in some other way' ( $\tau \tilde{n}$ ó $\psi \varepsilon 1$

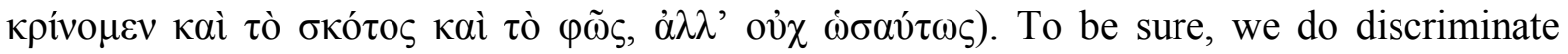
darkness from light by seeing as we look into a dark cave while we stand outside of it on a bright sunny day. However, the 'discrimination of darkness from light take place by sight 'in another way' when we perceive the lack of visual stimuli (darkness) in a completely dark environment. $^{20}$

The ability to perceive the lack of visual stimulation by sight is particularly important in this context, because if the experience has to count as a discrimination of darkness from light we must somehow be aware we are not seeing, it - otherwise, we would at best experience the mere deactivation of sight. ${ }^{21}$ What Aristotle seems willing to highlight in $\{8\}$, then, is that the fact that we can perceive darkness by sight casts doubt on the idea that we see that $F$ is being seen, while reminding us that sight can perform cognitive operations beyond seeing. ${ }^{22}$

${ }^{19}$ Johansen (2005: 246-248) notes it is unlikely that 'that which sees' ( $\tau$ ò ó $\left.\tilde{\omega} v\right)$ indicates here 'the activity of seeing', for reasons concerning both the meaning and the grammar of the expression. With regard to grammar, 'given the rarity of the locution in classical Greek, it is highly unlikely that Aristotle uses it here; (...) even if we did take the idiom to be used here, it would still retain, according to Denniston, a reference to the part or the whole of the person in its activity of seeing, that is to say the faculty or the person seeing' (ibid.: 247-8). In terms of meaning, it makes sense to say that sight has color as it is seeing, but not that the act of seeing itself has color: a 'fence becomes colored in the act or activity of being painted, but it is not the act of being painted that has the color' (ibid., 246). The latter point, however, seems to neglect that Caston's thesis is based on the idea that the 'seeing' is only phenomenally colored (cf. n. 28 below).

${ }^{20}$ The remark reminds us that senses discriminate both the presence and the lack of differences between themselves and perceptible properties in the relevant range: we discriminate silence by our auditory sense, darkness by sight, intangible air around us by touch (cf. DA II 9 421b3-8; 10 422a20-31; 11 424a10-15).

${ }^{21}$ Cf. Gregoric,2007: 184-6, who attributes this capacity to the common sense.

${ }^{22}$ According to a different reading, supported by Johansen $(2005,50)$, the reasoning would instead be that 'if it is by sight that we perceive that we are not seeing (...), then that seems to lend support also to the idea that it might be by sight that we perceive that we are seeing'. Johansen also believes that $\{8\}$ 
In $\{9\}$, Aristotle will continue in the same direction set in $\{8\}$ and offer a clear reason why the perception of one's seeing cannot be an instance of 'seeing' $\{9\}$. The invocation of the idea that in perception we receive forms without matter indicates that the 'coloration' of sight is merely 'mental', and thus deprived of the causal efficacy associated with physically colored, actually visible things. It is therefore impossible that we perceive that we see by seeing 'that which sees'.23

Since the notion of 'receiving forms without matter' invoked in $\{9\}$ is one of the most debated aspects of Aristotle's theory of perception, the reading of the passage I just proposed needs to be clarified and defended. On the grounds of their own reading of the formula 'receiving forms without matter', some commentators think that Aristotle is here conceding that we can, after all, see 'that which sees', since the latter is somehow colored. ${ }^{24}$ The hypothesis would be that the same 'causal mechanism' by which one sees $F$ is at the basis of the 'perception that one sees $F$ '- even though some details of the account may be problematic. $^{25}$ This would indeed make the operation a case of higher-order seeing. Against

offers two examples of 'perceiving that one is not seeing': in one case, the absence of colours is due to the excess of light; in the other, to its absence (cf. also Polanksy, 2006: 382-384).

${ }^{23}$ To be sure, in Sens. 2 (437a26-b9), Aristotle admits that the eyes can see themselves, but this only happens in exceptional and abnormal cases, under the specific circumstances that make an eye exceptionally visible to itself. From this perspective, what Aristotle says in 437a26-29 is that if there were fire in the eye, the eye should always see itself (not just when it is being rubbed). Arguing that we see the fire but we fail to notice it is not acceptable, because 'it is not possible for somebody who is

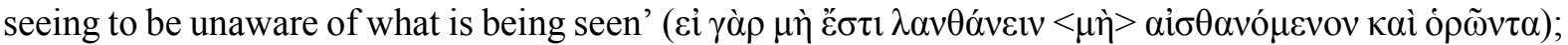
with regard to the latter sentence, cf. Johansen's (2005: 266, n. 64) criticism of Caston (2002: 758), who reads the sentence as 'it is not possible to be unaware of perceiving and seeing something seen' (on the latter question, cf. n. 40 below). Analogous 'affections' that give rise to after-images and perceptual illusions are described in Insomn. 2 (459b 3-23). Along similar lines, DA II 10 (422b6-10) admits that, due to disease or the impairment following the interaction with an intense perceptible object, a tongue becomes full of sour moisture and thus perceptible to itself.

${ }^{24}$ Ross (1961: 275); Kosman (1975: 512); Osborne (1983: 402, 404); Johansen (2005: 250-252), Polanksy (2006: 383); Gregoric (2007: 180).

${ }^{25}$ Johansen (2005: 250-252) notes that either a literal or 'spiritual' interpretation of the coloration can do the job, provided that the (literal or 'phenomenal') 'coloration' is a suitable causal antecedent of perception. On both interpretations this is indeed the case, since they assume that the media of perception are also colored by receiving forms without the matter. As Johansen admits (ibid.: 267-268), however, this raises the question of how second-order perception, located in the perceiver, could satisfy the requirement, posed for first-order perception, of a distance separating the perceiver from the perceived. Along similar lines, cf. Marmodoro, A. (2014). Aristotle on Perceiving Objects. Oxford University Press, 197-8. Marmodoro notes that $\{9\}$ is a second and 'merely speculative' answer to the puzzle about the coloration of 'that which sees', since it entails some difficulties ('there should be a vantage point of observation for the sense to observe itself in operation. (...) Secondly, Aristotle has clearly explained that on his account the sense organ does not receive and take on perceptible qualities in the way that the object perceived possesses such qualities'). 
this view, I believe that it is mistaken to derive from the reception of 'forms without matter' by sight the thesis that 'that which sees' is red in the same way as the tomato the perceiver is seeing is red, or even red in the same way as the transparent medium between the perceiver and the tomato is red.

A complete survey of Aristotle's works can show that his consistently non-adverbial use of the clause 'without (the) matter' describes forms that, lacking any matter whatsoever, are 'causally powerless' and 'metaphysically sterile' abstractions being cognized in one's mind. What this means is that such (matter-less) forms do not perform the tasks assigned to forms in Aristotle's hylomorphic metaphysics, namely the tasks of furnishing subjects with their identities (in the case of substantial forms) and qualifications (in the case of accidental forms). ${ }^{26}$

A thing that receives an ' $F$-without-matter' does not become an $F$-thing; and thus, it does not possess the causal efficacy that belongs to $F$-things, either. It is for this reason that, in $D A$ II 12, Aristotle considers being capable of receiving 'perceptible forms-without-the-matter' a generally sufficient condition to define perception. The perceptible forms of which perception is receptive are 'without the matter', like the 'iron-less' and 'gold-less' signature that belongs to an iron or golden signet-ring - an 'abstract' entity corresponding to the shape that a wax block can receive from the ring as a form-in-the-matter (DA II 12 424a18-20). ${ }^{27}$

The 'matter-less' color of $D A$ III 2, then, does not 'tinge' the faculty of sight to the effect of making it actually visible. Instead, Aristotle's notion of 'forms without the matter' poses an implicit distinction between a perceptible $F$ property (a form-in-matter) and what we would describe as the 'mental' or 'phenomenal' $F$ (a form-without-matter). As a consequence, the perceptual faculty or the act of seeing is 'painted' in 'mental paint' — and thus colored in a certain way, i.e., just phenomenally. ${ }^{28}$ The phenomenal 'redness' received by sight through

\footnotetext{
${ }^{26}$ Two groups of occurrences of the clause 'without the matter' can be distinguished: in the first one (including Phys. II 2 194a14-15; Cael. I 9 278a23-24; DA III 4 429b14; Metaph. IV 1 1026a6; XII 6 1071b19-22; VII 10 1035a20-23, 28-29;), the clause refers to subjects (and corresponding formulae) that are 'definitionally matter-less'; in the second (which includes $G C$ I 5 322a28; 10, 328b12-13; DA III 4 430a3-8; 6 430b30; 12 434a28-30; Metaph. XII 3 1070a14-17; 9 1074b38-1075a3), the clause refers to causally powerless and metaphysically sterile forms. For a detailed analysis of those passages I must refer, for obvious reasons of space and convenience, to Grasso, R. (2013). Receiving Forms without the Matter in Aristotle's DA II 12. Philosophical Inquiry, 36 (1-2), 29-38.

${ }^{27}$ For a complete argument in favor of this interpretation, cf. Grasso (2013: 38-43).

${ }^{28}$ I therefore largely agree with Caston's (2002: 788-791) observations about the phenomenal quality of experience we can attribute to Aristotle on the ground of the passage, especially when he stresses that Aristotle, unlike a sense-datum theorist, does not theorize that 'our experience contains objects that possess perceptible qualities quite literally'. In Aristotle's words, there is no reason to believe that colors
} 
causal interaction with the tomato's visible redness is not an equally causally powerful replica of either the redness of the tomato or the redness of the illuminated transparent medium.

As the visual faculty of the soul sees red, it is somewhat 'determined' by that form without being qualified by it in a physical way: the visual faculty of the soul does not take on the causal efficacy of things that are colored in a primary way, since the visual faculty of the soul is not something visible in the first place. The point Aristotle makes in $\{9\}$, then, is that the operation of perceiving that one sees will have to access some perceptual content $F$ without interacting with causally efficacious $F$-objects. As the example of perceiving darkness by sight has showed in $\{8\}$, such a thesis is less exotic and scandalous than it might prima facie appear.

\section{The 'Object Inclusion' Claim}

We can now go back to the first part of $D A$ III 2, trying to 'reverse-engineer' the controversial argument Aristotle presented there. The first question I shall deal with concerns the 'Object Inclusion' remark Aristotle makes in $\{3\}$.

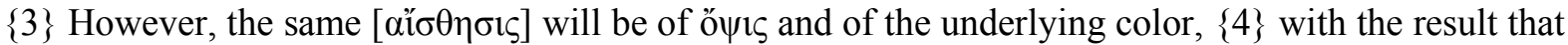

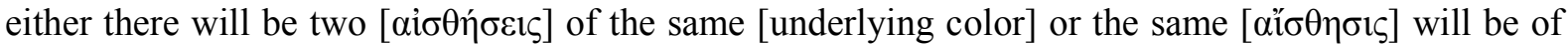
itself.

While we can keep being neutral with regard to whether Aristotle is asking a question about senses or sensations, the 'object inclusion' claim makes it obvious that the genitive 'of sight' is, like the following 'of the underlying color', an objective genitive - the sense/sensation by which 'we perceive that we see' will be directed at the first-order ö $\psi 1 \varsigma$ and have it as its content. As we already observed in the introduction, however, both the grounds and the purposes of the Object Inclusion claim are far from clear: the claim is not self-evident, and its introduction is not sufficient to make any obvious progress with regard to the hypotheses posed in $\{2\}$ and re-proposed in $\{4\}$.

In this regard, it has been rightly observed that for Aristotle seeing is always of some visible object. ${ }^{29}$ This observation can even be strengthened by stressing that a sufficient

are 'secondary qualities' instantiated in the mental act of perceiving, to be contrasted with the geometrical and mechanical 'primary qualities' belonging to external objects. As Caston notes (ibid., 791), 'Aristotle can thus agree with the intentionalist that nothing other than perceptible objects need literally have the perceptible qualities in question. But he can also agree with the proponent of qualia that the phenomenal character of our experiences outruns their representational content'.

${ }^{29}$ Cf. Johansen (2005: 243). 
condition for 'seeing' seems to be nothing less than 'sight being at work on an $F$ which is visible in actuality'. Perceiving an $F$ that is visible in actuality is necessary, but not sufficient for seeing: minimally experienced blindfolded drinkers can easily perceive by taste, in a welllit room where everything is visible in actuality, the color of red wine, black coffee, white milk or orange juice. For a similar reason, the being at work of sight, while obviously necessary, is not sufficient for seeing, either - remove the blindfold and turn the lights off: the taster will now perceive darkness by sight, while perceiving the colors of those drinks.

Even though there is no seeing without sight being at work on an objects that are visible

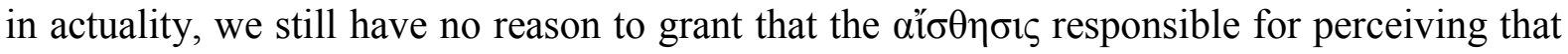
one sees must also include $F$, at least under the premise that the $\alpha$ li $\sigma \theta \eta \sigma ı \varsigma$ responsible for that operation is different from ö $\psi 1 \varsigma .{ }^{30}$ One may concede that seeing must include a visible $F$ on which sight is at work but refuse to accept that a further capacity that perceives that the firstorder activity is taking place must also perceive the latter's object. ${ }^{31}$ In fact, one can easily imagine a scenario in which sight emits a perceptible signal when it engages in seeing, and that some other sense perceives such signal. Supposing the signal was audible, this would be the capacity of hearing. ${ }^{32}$ Less awkwardly, one may imagine some proprioceptive feeling detected by a specific sense. In similar scenarios, the putative further sense that has the function of perceiving that sight is seeing would not need to include the $F$ object being seen, regardless of the fact that sight always sees some $F$. Claiming that Aristotle's 'perceiving that we see' is not the detection of the being at work of sight on a visible object (a detection that does not see that object), but, rather, the perception that the object being seen is being seen, is tantamount to begging the question. ${ }^{33}$

${ }^{30}$ Under the hypothesis that sight engaging in seeing is the aí $\sigma 0 \eta \sigma ı \varsigma$ responsible for the operation of perceiving that one sees, the inclusion of the 'underlying color' will be obvious.

${ }^{31}$ Along these lines, Osborne (1983: 403-404, 406-7) proposes that the underlying color must be included because what is detected is 'seeing', which is a specific type of activation of sight. The reason is that, on the basis of the second part of III 2 (425b26-426a26), seeing is identical with the actuality of color and thence 'transparent' (the same passage is quoted as a justification for the object inclusion by Gregoric 2007: 178). Osborne's justification does not seem to prevent one from perceiving the occurrence of (that specific type of activation of sight, namely) 'seeing' in an indirect way, i.e., by a perceptible indicator specifically corresponding to it (for a wholly different line of criticism concerning the 'transparency' of perception, cf. Caston, 2002: 782-785). Accordingly, the inclusion of the underlying object does not seem required - in the absence of supplementary reasons - to perceive that the activation at play is 'seeing' rather than, say, 'tasting', as Osborne proposes.

${ }^{32}$ Cf. the hypothesis entertained — and rejected — by Kosman (1975, 203-504).

${ }^{33}$ To be sure, once the object inclusion thesis is accepted, it is no longer sufficient to get the information that 'we perceive' without the inclusion of the object. Under that premise, the operation Aristotle has in mind could not be, for instance, a proprioceptive feeling that sight is at work. Along these lines, 
In order to why Aristotle is so confident about the necessary inclusion of the underlying color (or sound, etc.), we should appreciate that the inclusion seems to be an unavoidable consequence of perceiving one's own seeing (or hearing, etc.). To clarify the point, let's suppose that the information that 'sight is at work on a visible object $F$ ' is provided by an

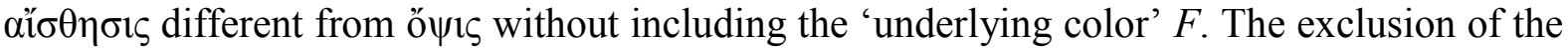
underlying object requires that the information accessed by that $\alpha$ i $\sigma \theta \eta \sigma ı \varsigma$ is separated from the

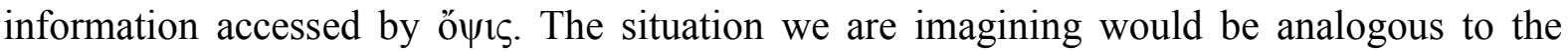
following example: a certain subject (S1) is walking down a street and meets a blindfolded person (S2) wearing a sign $(F)$ saying 'hug me'; as S1 plays along and hugs S2, S2 perceives that $\mathrm{S} 1$ sees $F$ while $\mathrm{S} 2$ does not see $F$. In such a scenario, the 'underlying object' requirement is avoided, but the 'perceiving that one sees' we are now considering is not an instance of perceiving one's own seeing. In order to make sure that S2's 'object-less' detection of S1's seeing contributes to the perception of one's own seeing (or hearing, etc.), it seems necessary

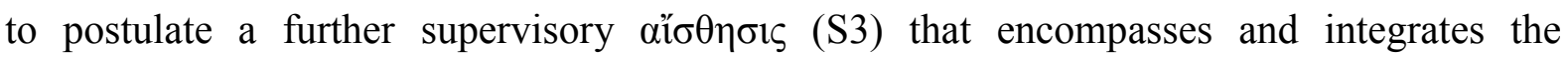
experiences and contents accessed by S1 and S2. The addition of this 'third party' supervisor, however, would entail the satisfaction of the 'underlying object' requirement: the supervisory

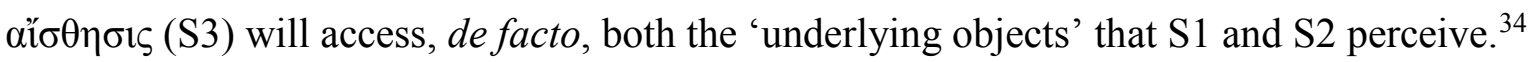

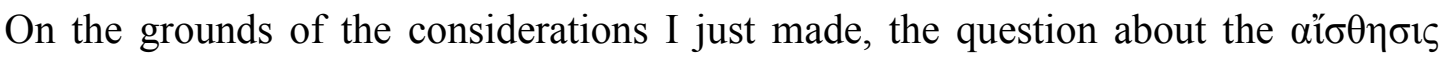
responsible for perceiving one's own seeing engenders the following hypotheses:

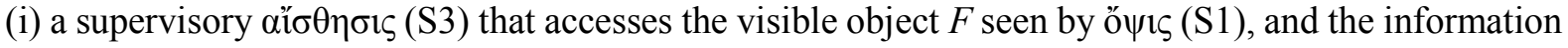

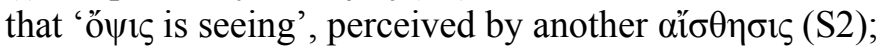

(ii) a supervisory ai̋ $\theta \eta \sigma 1 \varsigma$ (S2) that perceives both the visible object $F$ seen by ö $\psi 1 \varsigma$ (S1) and that ö $\psi 1 \varsigma$ is seeing;

(iii) the first ö $\psi 1 \varsigma$ (S1) will see the visible object $F$ and perceive that it (S1) is seeing that object $(F)$.

Caston (2002:771) notes against Osborne (1983) that the 'Object Inclusion' thesis excludes that the perceiving that we see is simply 'a matter of being informed that we are seeing, rather than merely dreaming; or discerning that we are seeing rather than, say, hearing'. What is still unclear, however, is the rationale for the very same idea that the 'underlying object' of the first-order activity must be included.

${ }^{34}$ What this 'third party' model would not entail, on the other hand, is the 'centralized' connection of the five senses: theoretically, one could apply the model to each of the senses separately and hypothesize as many 'detectors' and 'supervisors'. It is important to add that the required unification of S1's and S2's contents is not an automatic consequence of the fact that S1 and S2 are 'parts' of a single subject $\mathrm{S}$. This is one of the points Aristotle will make in his forthcoming treatment of the discrimination of the difference between white and sweet (DA III 2, 426b 17-23). 
These options perfectly correspond to what Aristotle says in $\{4\}$ : in (i) and (ii), two

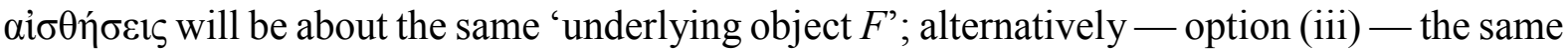
ő $\psi 1 \varsigma$ will be of itself. In all cases, the 'underlying object' $F$ will be included, as Aristotle points out in $\{3\}$. The remark about the inclusion of the underlying object, then, is not an arbitrary requirement, nor an argumentative premise (of dubious efficacy) related to the doctrine of proprietary objects of $D A$ II 6 ; it is, rather, an acknowledgment of what goes on when one perceives one's own seeing - the operation will abide by the schema 'S perceives that $\mathrm{S}$ sees $F^{\prime}$ and the inclusion of $F$ will be unavoidable.

If we look at the final part of the argument, it is reasonable to suggest that Aristotle decides to uncover and highlight the 'object inclusion' implication to prepare the claim he makes in $\{9\}$, where he clarifies that the included object — the 'underlying color' — is not the type of thing we can see (it is not a causally efficacious property capable of acting on a sense organ), but, rather, an abstract matter-less form. ${ }^{35}$

With regard to the question of whether Aristotle is reasoning about perceptual capacities (senses) or activities (sensations), it seems harmless to keep a neutral stance. At this stage, none of these options - in particular, the model based on the naïve idea of an 'inner eye' seeing the outer eye - need to be considered a serious candidate for explaining how we 'perceive that we see'. It is sufficient that such possibilities are at least theoretically viable. ${ }^{36}$

The Regress

In 425b15-17, Aristotle continues his reasoning by posing a condition that supposedly produces an infinite regress. The passage reads:

${ }^{35}$ The 'Object Inclusion' remark is therefore valid, in my view, for both the horns of the initial, 'purely logical' dilemma posed in $\{2\}$. As Caston (2002: 735, n. 35) notes, the restriction of the 'Object Inclusion' thesis to the 'another aî $\sigma \theta \eta \sigma ı \varsigma$ ' horn of the first dilemma is instead supported by Alexander (Quaest. 3.7 91-2), Themistius (In De an. 83.13); Ross (1961: 275 ad loc.), and supplied in translation by Wallace, Rodier, Hamlyn, Tricot and Barbotin.

${ }^{36}$ Caston (2002: 768) argues that the capacity reading of the expression 'the same one will be of itself' employed by Aristotle in $\{4\}$ (425b15) must be 'the same capacity is of its own activity', thus relying on a change of referent that is implausible in such a short phrase. According to Johansen (2005: 242243), however, 'Caston's point relies on an artificially narrow idea of how to read reflexive expressions such as "seeing oneself"'. Caston (2002: 770-772) also suggests that the hypothesis of a second visual act of perceiving entails a phenomenologically implausible 'double vision' of the same object. I believe that Aristotle is not yet excluding even that hypothesis (namely, a 'double vision' model) at this stage, and that the rebuttal is only obtained - on logical rather than phenomenological grounds - at the end of the argument. 
$\{5\}$ Further, were the $\alpha$ il $\sigma \theta \eta \sigma i \varsigma$ of ö $\psi 1 \varsigma$ different, $\{6\}$ then either this will carry on into infinity or there

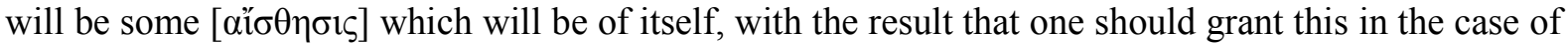

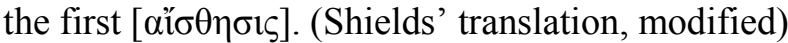

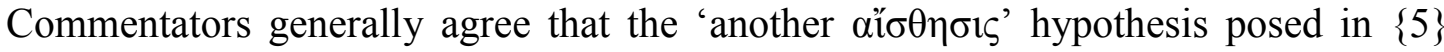

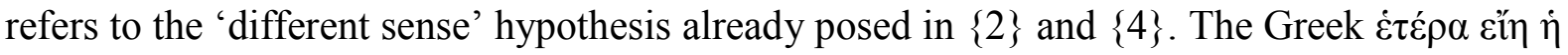

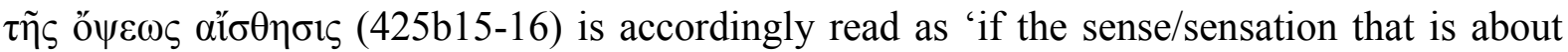
sight/vision is different from sight/vision. The idea, then, is that the regress argument works towards the conclusion that not only seeing, but also perceiving that we see, must be attributed to the first $\alpha$ ï $\sigma \theta \eta \sigma 1 \varsigma$ ('sight', or 'vision').

As anticipated in the introduction, the regress argument presented in $\{6\}$ would seem sound if one assumed that the activity of 'perceiving that we see (and hear, etc.)' were the 'being aware' that intrinsically belongs to every act of perceiving; on the other hand, this assumption requires an unconvincing reading of the expression 'perceiving that we see (and hear, etc.)', since the phrasing hardly suggests a type of 'perceiving' that 'intrinsically belongs' to seeing (and hearing, etc.). On the contrary, the idea of a perceptual operation directed at the first-order act of seeing (or hearing, etc.) - a much more natural reading of the expression 'perceiving that we see (and hear, etc.) - seems to fall short of entailing the actual regress Aristotle denounces in $\{6\} .{ }^{37}$

With regard to the challenge posed by modern commentators against the traditional reading of the regress argument, I propose that $\{5\}$ should be read as a description of the

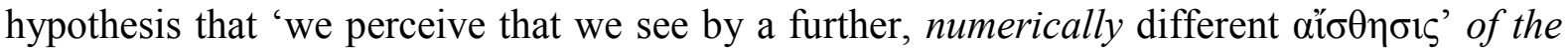
same type (not by a different type of aí $\sigma \eta \eta \sigma 1 \varsigma$ ), thus rejecting the idea that $\{5\}$ is a reproposition of one of the options already introduced in $\{2\} .{ }^{38}$ The implicit assumption that

${ }^{37}$ In this regard, Johansen (2005: 244-245) seems happy with a potential explanatory regress about faculties: 'what generates the regress is not the requirement that any act perception actually be perceived. (...) The thought is that at each level of perception, where that perception is itself perceptible, a further faculty has to be posited in order to explain how that perception can be perceived'. With regard to the efficacy of Johansen's account, I share the doubts expressed by Kosman, L. A. (2005). Commentary on Johansen, Proceedings of the Boston Area Colloquium in Ancient Philosophy, 21, 280282 (cf. also Corkum 2010: 206-207). Johansen's related comparison with the Third Man argument (ibid.: 245, n.16) is not entirely persuasive, either: with regard to Forms, the 'bottom level' represented by the individual subjects is always and only working as the explanandum, never as the explanans (a Form $F$ may explain why a particular $F$ is $F$, but certainly not the other way around); in the case of senses, the asymmetry is not warranted, and it is theoretically possible to break the regress by theorizing, for instance, that while sight's activity is perceived by $x$ (a sense different from sight, which at this point in the argument may be another one of the five senses), $x$ 's activity is in turn perceived by sight.

${ }^{38}$ The further specification made in $\{5\}$, according to which the numerically different sense or sensation we are hypothesizing is 'of sight', can then be read as either an objective or subjective genitive: in the first case, Aristotle refers to a numerically different sense/sensation that is about ob $1 \mathrm{c}$; in the second 
leads one to postulate 'another aî $\sigma \theta \eta \sigma ı \varsigma$ ' is that the initial sight/vision can perceive a

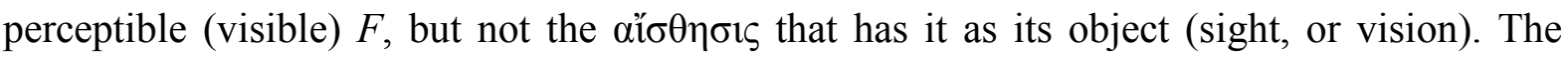
assumption, in other words, is that 'red' and 'middle C' can be seen and heard respectively, but

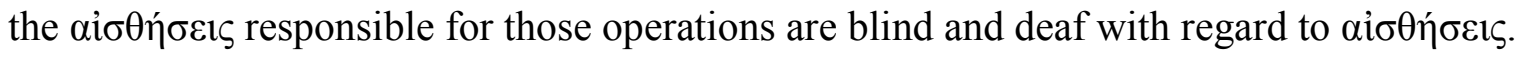

The gist of Aristotle's regress argument is that one could be misled into thinking that

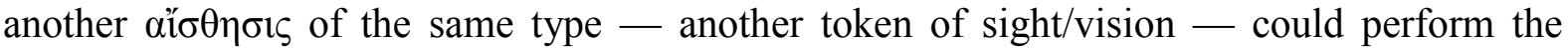
required job by seeing that $F$ is being seen (or by hearing that $F$ is being heard, etc.). A second token of the same type, however, will be as blind and deaf with regard to $\alpha i \sigma \theta \eta \dot{\sigma \varepsilon ı \varsigma}$ as the first one - at best, it will only re-perceive what the first one perceived already, i.e., the underlying object $F ;^{39}$ and, by the explanatory policy one had advocated, one would have to recursively postulate another $\alpha i \sigma \theta \eta \sigma 1 \varsigma$ of the same type, and so on ad infinitum. To stop the regress, one could, of course, assume that, at some point, some token of that type would not be blind to $\alpha i \sigma \theta \eta \dot{\sigma \varepsilon ı \varsigma}$; but in this case, it would be better to spare the effort and attribute this ability directly to the first ö\%is.

While the regress recognizes that the hypothesis of a 'first order self-seeing' o' $\psi 1 \varsigma$ is still theoretically viable, we have already shown that Aristotle is going to argue against the surviving hypothesis that one could perceive 'that which sees' in the same way as one sees some $F$ that is visible in actuality. Accordingly, there is no reason to believe that the first of $\psi 1 \varsigma$ could see itself by the same mechanism by which it sees the external visible objects. In fact, we cannot see our own sight as it engages in seeing, since 'that which sees' is colored only in a certain way (i.e., phenomenally), and not to the effect of being visible. The hypothesis of a 'first order self-seeing' ö $\psi 1 \varsigma$ is, in the end, rejected: the theoretically valid hypothesis is that

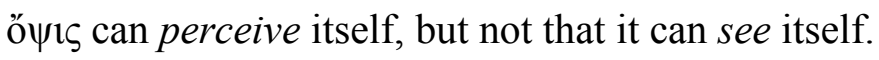

As a corollary of the interpretation I just proposed, the regress argument does not compel us to attribute to Aristotle the claim that it is physically or logically necessary that 'seeing $F$ ' and 'perceiving that $F$ is being seen' co-occur. In this regard, other texts that have been quoted from other works by Aristotle are also ambiguous and hardly decisive. ${ }^{40}$ In $E N$ IX

case, Aristotle would clarify that we are considering the hypothesis of a numerically different sense/sensation belonging to the same type as the first ö $\psi 1$ c

${ }^{39}$ If one anticipated the results of the puzzle about the coloration of 'that which see', it would not even

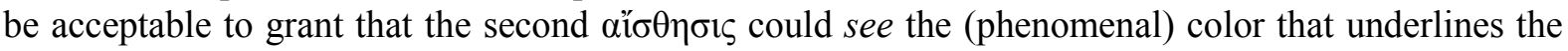

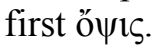

${ }^{40}$ With regard to these passages, I follow the results of the analysis offered by Johansen (2005: 263266), who disputes the reading offered by Caston $(2002: 757-759,774-775)$ and embraced by Gregoric (2007: 188) and, more ambiguously, by Polanksy (2006: 385). 
9 1170a29-b21, one can take the text attested by the manuscripts to mean that we do not always perceive that we see or hear. What the passage aims at showing is that we take pleasure in our own existence, and the argument does not seem to require that we are always aware that we perceive. Similarly, Metaph. XII 9 1074b33-6 only states that perception (like opinion and

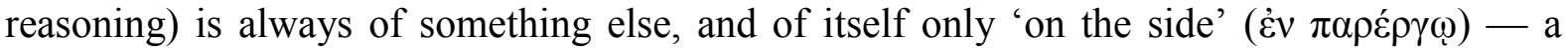
formula that does not entail a secondary activity that is always taking place. Finally, the passage contained in Phys. VII 2 (244b12-245a2, version $\alpha$ ) does not need to indicate anything more than the following idea: in contrast to inanimate beings, animate beings are affected $\kappa \alpha \tau \grave{\alpha} \tau \hat{\alpha} \varsigma$

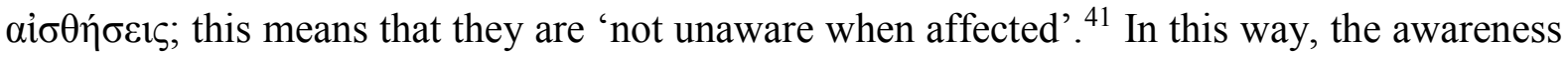
at stake is the 'phenomenal consciousness' that belongs to the first-order act of perceiving, not the 'perceiving that we see' of $D A$ III $2 .{ }^{42}$

\section{The Type of Perception by Which We Perceive That We See}

According to the reconstruction I proposed, sections $\{7\}-\{9\}$ support the claim that we do not see that we see, suggesting instead that the perceptual activity at work accesses an $F$ content without a genuinely physical causal interaction with an actually perceptible $F$-object. ${ }^{43}$ In this regard, it is important to note the resemblance between the latter way of perceiving $F$ (with no causal interaction with $F$-objects) and the notion of per accidens perception.

${ }^{41}$ On this reading, the $\kappa \alpha i$ in $244 b 15$ is epexegetic. The passage is read by Caston (2002: 757) as contrasting inanimate and animate beings on the basis of two differences: in contrast to inanimate

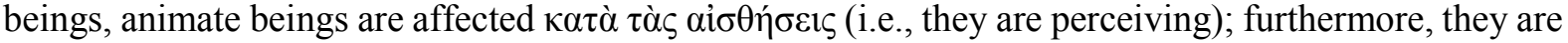

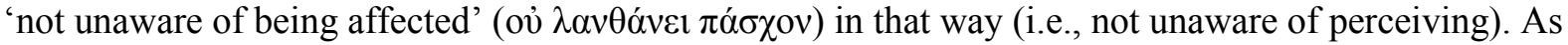
Johansen (2005: 264-265) notes, on this view 'the second contrast now seems oddly irrelevant: of course, inanimate objects do not perceive themselves perceiving since they do not perceive in the first place'.

${ }^{42}$ A related, but distinct question with regard to which III 2 offers no clue is whether the (necessary or merely possible) co-occurrence of these two operations - 'seeing $F$ ' and 'perceiving that $F$ is being seen' - gives rise to a single token of a certain type of 'perceiving' (characterized by the fusion of those two aspects), or to two tokens that belong to different types of 'perceiving'. The decision seems to depend on one's stance with regard to the identification of tokens of mental events on the basis of their content. On this issue, cf. Caston (2002: 781-782) and Johansen (2005: 257-260).

${ }^{43}$ What I mean by 'genuinely physical causal interaction' is a causal interaction that abides by the model Aristotle recalls at the beginning of DA II 5 (417a17-20): the agent and the patient (e.g., a hot body and a cold body) are actually similar on a generic level (they both have 'thermal' properties) while they are actually dissimilar and potentially similar on a specific level (the cold body has the potentiality to become hot as a result of the causal interaction with the hot body); as a result of this specific similarity, the causal interaction can make the patient become similar to the agent (the cold body can become hot as a result of the causal interaction with the hot object). 
The notion of per accidens perception seems to capture the essential feature of the activity that, in my view, is responsible for perceiving that one sees (or hears, etc.): $F$ is perceived without a genuinely physical interaction between a specific sense organ and the $F$ property of an $F$-object. Aristotle employs that notion in his explanation of how the senses perceive one another's 'proprietary' objects: one can perceive unripe bananas as 'bitter' by seeing their green color, without actual causal interaction between their taste and the tongue. To be sure, that operation is only possible if one has previously perceived that bitter taste and that green color as a unitary object (cf. DA III 1 425a30-425b3). However, on the grounds of past experience, it is possible to perceive that green bananas are bitter even when no sense interacts with the bitterness of the banana in the same way that our eyes do when they see its greenness. This situation is similar, I submit, with regard to perceiving 'that which sees' and the phenomenal color that characterizes it: none of the five senses causally interacts with the matter-less redness that underlies our sight/vision in the same way that our eyes are interacting with the redness of the tomato.

One may object that there is an obvious difference between the two cases: when one perceives per accidens the taste of some fruit just by seeing its color, the lack of causal interaction is due to the fact that the $F$-property that could interact with one of the sense organs is absent or not actually perceptible; in the case of perceiving 'that which is seeing' and the phenomenal color that characterizes it, however, the $F$-property that corresponds to the $F$ content is not the type of thing that could affect any sense organ in virtue of a genuinely physical causal interaction: there is simply no circumstance in which the matter-less redness is 'perceptible' in that sense of the word. With regard to the objection I just raised, however, one may note that Aristotle's notion of per accidens perceiving seems to include all cases in which a property is perceived without a genuine causal interaction with a specific sense organ, without distinguishing those that could interact with some specific sense organs from those that simply cannot. This is confirmed by Aristotle's introduction of the idea of per accidens (or 'coincidental') perception in $D A$ II 6 :

Something is said to be an object of perception co-incidentally if, for example, the white thing should be the son of Diares. There is co-incidental perception of him, because he coincides with the white thing, of which there is perception. For this reason, one is not affected by an object of perception insofar as it is such a thing as the son of Diares. (DA II $6418 \mathrm{a} 20-24$, Shields' translation)

None of the sense organs could ever causally interact with the property 'being a son of Diares' in the same way as our eyes do with his whiteness, even when that property belongs to the white object we are seeing. In this sense, the situation is perfectly analogous to the 
perception of 'matter-less' mental states, that are not specific to any sense. ${ }^{44}$ Furthermore, we can once again note that the type of experience to which Aristotle alludes is not as outlandish or exotic as it might appear. What he describes is the same type of cognitive activity you could perform at a friend's wedding by perceiving that the person in front you, whom you have never met before, must be your friend's soon-to-be father-in-law.

The fact that the ability responsible for the perception of perceptual states of the various senses is not bound to any specific sense emerges more clearly in De Somno 2, where Aristotle develops some implications of the claim, already established in $D A$ III 2, that we do not in fact see that we see:

every sense has something special and also something common; special, as, e.g., seeing is to the sense of sight, hearing to the auditory sense, and so on with the other senses severally; while all are accompanied by a common power, in virtue whereof a person perceives that he sees or hears - for by sight one certainly does not see that he sees; yet, one certainly discriminates it. (Somn. 2 455a13-18, Beare's translation, modified)

By theorizing a common ability possessed by each of the five senses, Aristotle seems willing to exclude the possibility of five abilities, each perceiving one specific type of perceptual activity with the specific 'forms without the matter' that characterize it (seeing and the matter-less colors; hearing and the matter-less sounds; etc.). The distinction of five abilities to perceive five specific types of perceptual states would arguably have to refer to each of the five organs and its ability to causally interact with just one type of perceptible qualities. However, if - as I have suggested - the causal interaction between specific sense organs and specific types of actually perceptible $F$-objects is not relevant for the operation of "perceiving that we see $F$ ', it seems more reasonable to claim that 'we perceive that we see' by a common power that belongs in the same way to all the five senses, without being specified in five subpowers for each of them. ${ }^{45}$

\footnotetext{
${ }^{44}$ I therefore agree with Johansen (2005: 260) as he observes that perceiving that we see and hear 'will generally qualify as a form of accidental perception', even though his justification of this claim is different from mine. According to Johansen, the perception is accidental because it involves 'attributing this color to one's own sense of sight', thus requiring a unification of 'that we see' and (e.g.) 'red' that in his view cannot be carried out by sight (ibid., 270-273).

${ }^{45}$ It is only by the further remarks about cross-modal perception (the type of activity involved in discerning white things from sweet things, for instance), expounded in 455a18-22, that Aristotle justifies the further claim that all the senses are in fact modalities of a unitary system (the two points seem to be conflated by Johansen (2005: 270-273)). A different view is proposed by Osborne (1983: 406-407), who believes that the argument for the attribution of the perception that we see to a common power is contained in DA III 2 as a whole (in order to perceive that a color is being seen, rather than heard, we need a sense that can discriminate the difference between colors and sounds). Caston (2002: 778-9) thinks that $D A$ III 2 intends to show the numerical unity of the perceptual activity (seeing) and
} 
The conclusion of the section of $D A$ III 2 we are examining seems to confirm the link between 'perceiving that we see and hear' and the accidental perception of features which are inaccessible by per se perception:

$\{10\}$ And for this reason perceptions and imaginings are there in the sense-organs even when perceptibles are gone (425b24-25, my translation)

Since Aristotle has not yet expounded his views on $\varphi \alpha v \tau \alpha \sigma i \alpha$ (he will do this in DA III

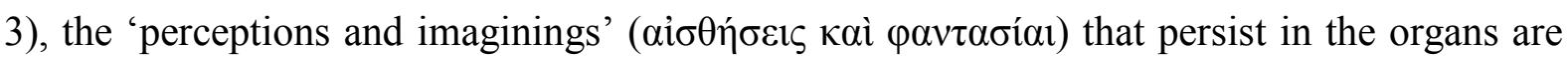
likely those that allow the 'per accidens' perception of contents that have been 'per se' perceived in the past, such as the perception of the bitterness of unripe fruit we see, when no bitterness is affecting our tongue. What has been established in the preceding lines does indeed provide an explanation of our ability to perform those tasks: perceptual operations about $F$ take place in the sense organs when $F$ is not present because 'perceiving' is not limited to 'perceiving $F$ by causal interaction with $F$ ', as established in $\{8\}$; as we saw in $\{9\}$, the $F$ which is being seen can be perceived despite its being matter-less (purely phenomenal and causally inefficacious).

The link Aristotle establishes between the accidental perception of $F$ and the operation of 'perceiving that $F$ is being seen (or heard, etc.)' becomes even clearer in his De Memoria. In that work, he seems to suggest that we perceive the 'bitterness' of the green bananas we are seeing because we are able to 'perceive that we saw such color \& tasted such taste'. For he states that:

when someone is actively engaged in memory, he perceives in addition that he saw this, or heard it, or learned it earlier. (Mem. 1 450a19-22) ${ }^{46}$

Later in the same work (451a2-7), Aristotle adds that it is because 'we have a thought

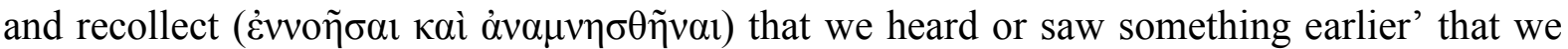
know whether a certain image is rooted in previous episodes of perception or not - without knowing in some way that we heard or saw some object, it is possible that our current mental state be the result of hallucinations or random combinations of the features of stored perceptual affections ( $(\alpha v \tau \alpha \sigma i \alpha)$ ). The ability to perceive that 'we are seeing and hearing', then, seems to be a necessary step to test whether mental states are reliable remnants of past experience. In

its intrinsic awareness, whereas Somn.2 ascribes this awareness, common to all perception, to the perceptual capacity as a whole.

${ }^{46}$ Translations from De Memoria are from Sorabji, R. (1972). Aristotle on Memory. Duckworth. 
this view, one can either entertain such 'reliable' mental states in themselves, to think about certain things or types of things that are accessible to experience; or entertain them as 'of something else', to remember singular events and individual objects we have experienced in the past (Mem. $1450 \mathrm{~b} 20-451 \mathrm{a} 2)$.

If we bear in mind the views Aristotle expounds in De Memoria, $\{10\}$ may indeed be claiming that the reason why we can perceive $F$ when $F$ is not directly accessible to our senses is that we can perceive that we see $F{ }^{47}$ The point would be that, for instance, we can 'accidentally' perceive the redness of the wine we are tasting even though we cannot currently see it, because we perceive that we saw this wine in the past. If this is correct, Aristotle concludes the section of $D A$ III 2's discussion about 'perceiving that we see and hear' by hinting at the fact that the ability to be aware of one's own perceptual states is the reason why one can perceive $F$ accidentally. ${ }^{48}$

The connection with Aristotle's treatment of accidental perception offers the possibility to resolve a possible concern entailed by the notion of perceiving $F$ in the absence of a genuinely physical causal interaction with $F$-objects. None of the examples Aristotle proposes seems to suggest or entail the lack of underlying physiological processes. In fact, he seems to think that even though one perceives some $F$ content without causally interacting with some $F$-objects, this operation is always accompanied by a causal interaction with some property $G$ of a $G$-object. For instance, we see the 'white' and perceive accidentally that 'the white is the son of Diares'. ${ }^{49}$ Analogously, one may notice that the operation by which 'we perceive that we see $F$ ' does obviously co-occur with a causal interaction between sense-organs and some visible $F$ of an $F$-object. Thus, we perceive that we see in virtue of perceiving the mental act of seeing and the matter-less 'red' that characterizes it, but this operation takes place while our eyes causally interact with the actually visible 'red' of a red object. For this reason, the former operation will be no more 'de-physiologized' than the latter. ${ }^{50}$

\footnotetext{
${ }^{47}$ The parallel between $\{10\}$ and Aristotle's theory of memory has been rightly underlined by Johansen (2005: 262-263).

${ }^{48}$ I thus disagree with Caston (2002: 790), when he considers $\{10\}$ 'no more than gesture at an answer'. Along similar lines, Osborne (1983: 402) describes it as a 'footnote' that 'seems to have little relevance to the matter in hand except that it raises the question of our awareness of our seeing when what we see is only a phantasia in the organ'.

${ }^{49}$ With regard to the threat of a 'de-physiologized' perceptual activity, one should also note that in III

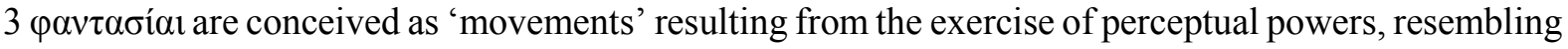
sensations and remaining in the sensory apparatus (DA III 3 428b27-429a8, cf. III 7 431a15-19).
}

${ }^{50}$ My point here must be limited to the observation that if you assume that seeing cannot take place without some co-occurring bodily changes in the visual apparatus, this will suffice to secure that 


\section{Conclusion}

If my reconstruction of the treatment of 'perceiving that we see (and hear)' in $D A$ III 2 is sound, the logic of Aristotle's argument revolves around his willingness to secure the introduction of a particular type of perception, that is different from the one involved in 'per $s e$ ' perception. The perceptual activity by which we perceive our own perception cannot be based on a genuinely physical causal interaction with $F$-objects since the perceptual content supplied by per se perceiving only exists as a causally powerless abstract $F$ in the perceiver's mind. This type of perceptual activity is a precondition for per accidens (or co-incidental) perception.

This understanding of the goal of Aristotle's argument justifies a somewhat 'neutral' and liberal approach to two of the research questions I originally posed in the first section. With regard to Q1, we can concede that the initial dilemma posed in $\{2\}$ is ultimately unresolved not only in $\{4\}$ but throughout the whole argument, including its last part. This does not mean that Aristotle is putting on display his incapacity to reach a conclusion, however. In fact, he is arguing that for all possible options covered by the initial dilemma (including, I would say,

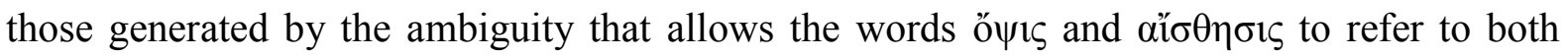
capacities and activities), and despite the acknowledgment that the 'underlying color' is included in the operation, we simply cannot see that we see. The text is not investigating the

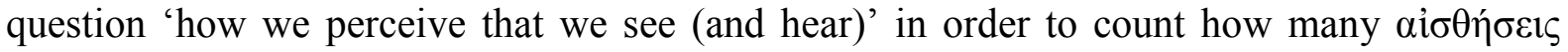
(senses or sensations) are involved in that operation ${ }^{51}$; what Aristotle wants to show is that perceivers can perceive their own private 'perceptual states', even though the properties that characterize those states (e.g., the matter-less, phenomenal redness), being causally powerless, are not perceptible per se (i.e., by ordinarily physical causal interactions with the sense organs).

'perceiving that we see' is not magically de-physiologized, either. Whilst one may still claim that in Aristotle's view both operations are deprived of any underlying physiology, I believe such a claim would be wrong for the independent reasons I explored in Grasso, R. (2019). Blind-Spots in Aristotle's Doctrine of the Perceptual Mean. Apeiron (online ahead of print version).

${ }^{51}$ In order to count 'how many activities and how many capacities' are involved in perceiving that we see, one should have a clear stance with regard to the question whether powers belonging to different types (the capacity to perceive a matter-less $F$ vs. the capacity to perceive by physical causal interaction with $F$-objects) must be numerically different - if this is the case, the 'common ability' of each of the five senses mentioned in Somn.2 will be numerically different from the capacity of each of the five senses to perceive their proprietary objects per se. Similarly, one can count sensations only after deciding whether perceptual activities with different types of contents (perceiving ' $F$ ' vs. perceiving that one is seeing $F$ ) must be different tokens (cf. note 42 above). The section of $D A$ III 2 we examined seems to offer no clue whatsoever to solve such questions. 
As a further consequence of the interpretation I offer, it becomes impossible to provide any reason related to the logic of the argument that could help in determining whether Aristotle is reasoning about senses or sensations (Q3). This liberality is for the better, though, since it allows me to offer an answer to our original question about the rationale behind the regress argument (Q2) that works for both the 'activity' and the 'capacity' reading. In $\{5\}$, Aristotle considers what happens if one postulates that the sense/sensation of ö 115 was a further, numerically different sense/sensation of the same type. This move would generate the regress denounced in $\{6\}$, since the requirement of a further sense/sensation assumes that the first one is blind to ö $\psi 1 \varsigma$, and a further sense/sensation of the same type will thus be blind to ö $\psi 1 \varsigma$ as well (it will just be able to perceive the underlying color once again); to avoid the regress, one should concede that, at some point, a certain token of that type will, in fact, display the ability to perceive an ö $\psi 1 \varsigma$. Thus, it would indeed be more reasonable to attribute this ability directly to the first sense/sensation, but the latter option has to face its own problems since it requires a coloration of 'that which sees' that makes the latter actually visible. In fact, no sense/sensation can perceive 'that which sees' $F$ by the same mechanism at the basis of seeing (per se perception of $F$ by causal interaction with $F$-objects), since our ơ $\psi 1 \varsigma$ is just phenomenally 'colored'.

In my view, then, the regress argument works without assuming that perceiving that we see (or hear, etc.) is the intrinsic 'phenomenal awareness' belonging to first-order perceiving. Thus, even though 'seeing $F$ ' and 'perceiving one's own seeing' may co-occur, their connection and co-occurrence are not due to some physical or logical necessity - and as we have seen, we have no text where Aristotle unambiguously claims that they always co-occur. ${ }^{52}$ Furthermore, since Aristotle is talking about a purely perceptual activity, it seems implausible that what is at stake is the conceptually demanding introspection sometimes performed by human beings. ${ }^{53}$ If the 'being perceptually aware that we see (and hear, etc.)' of $D A$ III 2 is

\footnotetext{
${ }^{52}$ It may be useful to compare the interpretation I offer with Caston's and Johansen's. According to Caston, the regress argument works because 'perceiving that we perceive' is the intrinsic awareness belonging to any act of perceiving; the co-occurrence between seeing and the intrinsic perceptual awareness of 'perceiving that one sees' is logically necessary and a single token instantiates the two, even though they belong to different types (perceiving that we see $F$ is directed internally, at a mental state; seeing is directed externally, at an actually visible object). According to Johansen, the regress argument does not refer to the intrinsic awareness belonging to first-order perceiving, but to a higherorder act of perceiving; perceiving that we see $F$ attributes the object being seen to one's sight, and for this reason is distinct and more complex in content in comparison to seeing; yet, in virtue of some causal mechanism that seems to be analogous to the mechanism responsible for first-order perception (Johansen 2005: 266-268), two activities may always co-occur by physical necessity.
}

${ }^{53}$ Cf. Johansen 2005: 257 with n. 45. 
neither introspection nor the phenomenal awareness intrinsic to seeing and hearing, what type of 'awareness' is it then?

The most likely candidate for Aristotle's 'perceiving that we see and hear' seems to be the 'awareness' that makes the perceptual experience of an absent-minded driver different from that of a driver deliberately attending to her own perception. The latter type of 'awareness' is the target of the explanatory model proposed by contemporary 'higher order perception' (HOP) theories of consciousness, also known as 'inner sense theories'. ${ }^{54}$ It is interesting to note, in that regard, that contemporary philosophers of mind have recently cast doubt on the assumption made by HOP theories that the 'being directed at something' of this type of awareness is representational, offering an alternative 'Attention View' (AV). According to this view, what constitutes one's consciousness of one's mental states is ordinary attention - the voluntarily 'directed' activity by which one attends to one's own mental states - which does not work by generating higher-order representations, as in classic HOP theories of consciousness. One's own mental states may be made 'aware' by attention, for instance, in virtue of a 'modulation' that selectively amplifies or suppresses some aspects of the representation towards which one's attention is directed. ${ }^{55}$

The doubt raised by the 'Attention View' against HOP theories can be illuminating with regard to the 'perceptual awareness' at play in Aristotle's 'perceiving that we see (and hear, etc.)'. If one assumes that a representation of $F$ is the result of a causal interaction between the perceptual apparatus and the $F$-object that is being represented, then Aristotle's view will de facto share, with regard to 'perceiving one's own seeing (and hearing, etc.)', the same antirepresentationalist stance that the 'Attention View' proposes with regard to 'being aware of one's own mental states' ${ }^{56}$ If one assumes that representations result from causal interactions,

${ }^{54}$ This is a famous example by Armstrong, often found in the literature on $D A$ III 2. I am sympathetic with Johansen's remark (2005: 274) that Aristotle is not 'offering either in DA III 2 or in De Somno 2 a general account of perceptual consciousness, if that is meant to explain also what makes first-order perception consciousness of objects in the world', and that Aristotle gives 'an account of what, thanks to Ned Block, has become known as "access consciousness," that is, the mechanism by which the contents of our mental state are available, or "poised," for rational control, verbal report, and reasoning' (ibid., 273-274).

${ }^{55}$ Sauret, W. \& Lycan, W. G. (2014). Attention and Internal Monitoring: A Farewell to HOP. Analysis 74 (3), 363-370.

${ }^{56}$ As far as HOP theories attempted to naturalize intrinsic phenomenal consciousness, I agree with Corkum (2010: 205) that one should be cautious in comparing Aristotle's thesis with contemporary views about consciousness, since '[h]is use of an embedded sentence within a "perceives that" clause may not indicate a substantive thesis about the nature of consciousness; it may just be a way of referring to an unanalyzed notion of consciousness or attention'. However, this worry may be less relevant to a comparison between Aristotle's thesis and the 'Attention View', which is, in fact, proposing attention 
Aristotle's 'perception of one's own seeing (or hearing, etc.)' cannot be representational because the 'phenomenal' color included in that perception is not something that could causally interact with the sensory apparatus. As a consequence, the particular type of 'perception by lack of causal interaction' characterizing Aristotle's 'perception of one's own seeing (or hearing, etc.)' may be understood as a precursor of the modern notion of 'non-representational attention' involved in the 'awareness of one's own perceptual experience'.

A welcome consequence of this understanding of 'perceiving that we see and hear' is that Aristotle's De Memoria would briefly explain that the ability to attend to our own perceptual states is the preliminary condition for (voluntary or non-voluntary) operations that select and manipulate the content of our experience. The importance of this type of 'perceiving' would ultimately explain why Aristotle took the time to secure its introduction by means of the complex — but regrettably obscure — argument of $D A$ III 2 .

Roberto Grasso University of Campinas

\section{Bibliography}

Caston, V. (2002). Aristotle on Consciousness. Mind, 111 (444), 751-815. https://doi.org/10.1093/ $\operatorname{mind} / 111.444 .751$

Corkum, P. (2010). Attention, Perception, and Thought in Aristotle.Dialogue, 49(2), 199-222. https:// doi.org/10.1017/s0012217310000247

Grasso, R. (2013). Receiving Forms without the Matter in Aristotle's DA II 12.Philosophical Inquiry, $36(1-2), 23-44$.

Grasso, R. (2019). Blind-Spots in Aristotle's Doctrine of the Perceptual Mean. Apeiron (online ahead of print version). https://doi.org/10.1515/apeiron-2018-0060

Gregoric, P. (2007). Aristotle on the Common Sense. Oxford University Press. https:// doi.org/10.1093/acprof:oso/9780199277377.001.0001

Hamlyn, D.W. (1968, 1993), Aristotle De Anima, Books II and III (with passages from Book I). Oxford University Press.

Hicks, R. D. (1907), Aristotle, De Anima. With translation, introduction and notes. Cambridge University Press.

Johansen, T.K. (2005). In Defense of Inner Sense: Aristotle on Perceiving That One Sees. Proceedings of the Boston Area Colloquium in Ancient Philosophy, 21, 235-276. https:// doi.org/10.1163/22134417-90000075

as an altogether different and non-representational process that constitutes 'access consciousness'. This effectively side-steps the dichotomy between considering perceptual consciousness of one's mental states as an intrinsic feature of first-order representations and reducing it to 'higher-order' ones. 
Kosman, L. A. (1975). Perceiving that We Perceive: On the Soul III, 2. The Philosophical Review, 84(4), 499-519. https://doi.org/10.2307/2183851

Kosman, L. A. (2005). Commentary on Johansen, Proceedings of the Boston Area Colloquium in Ancient Philosophy, 21, 277-283.

Marmodoro, A. (2014). Aristotle on Perceiving Objects. Oxford University Press. https:// doi.org/10.1093/acprof:oso/9780199326006.001.0001

Osborne, C. (1983). Aristotle, De anima 3.2, How do We Perceive that We See and Hear? Classical Quarterly, 33, 401-11. https://doi.org/10.1017/s0009838800034662

Polansky, R.M. (2007). Aristotle's De Anima. Cambridge University Press. https://doi.org/10.1017/ CBO9780511551017

Ross, W.D. (1961). Aristotle, De Anima. Edited, with introduction and commentary. Clarendon Press. Shields, C. (2016). Aristotle De Anima. Oxford University Press.

Sorabji, R. (1972). Aristotle on Memory. Duckworth. https://doi.org/10.5040/9781472598110

Sauret, W. \& Lycan, W. G. (2014). Attention and Internal Monitoring: A Farewell to HOP. Analysis 74 (3), 363-370. https://doi.org/10.1093/analys/anu055 